\title{
DECISION TYPE, STRUCTURE, AND PROCESS EVALUATION: A CONTINGENCY MODEL
}

\author{
MARVIN W. PETERSON. \\ Center for the Study of Higher Education, \\ University of Michigan, Ann Arbor, Michigan.
}

\begin{abstract}
Governance proposals for higher education in the United States are often promulgated on the basis of some utopian goal or on the assumption that a given proposal is the panacea for multifaceted problems or that it is equally applicable to diverse institutional settings. This paper, rather than promulgating a single proposal, takes a more analytic approach and develops a contingency model for identifying appropriate decision-making structures. First, emergent conditions in American higher education's external environment, in the internal social environment of its colleges and universities, and in the development of higher education management systems are analyzed to establish some long-range criteria for evaluating decision-making effectiveness. Second, a typology of institutional decisions categorized as policy, managerial, and operating decisions is presented. An analysis of the nature and content of each major type of decision suggests divergent patterns of formal and informal decision-making structures and patterns, and differing content and functions for the supporting management information technology which might be appropriate to each of the decision types or categories. Finally, the analysis relates the contingency notions of decision structure and type to the criteria for evaluating the decision-making process and suggests how they are compatible or might be modified to be more compatible. The model is a general conceptual one which the author suggests can be used on either an institution-wide basis or with particular subunits of a college or university.
\end{abstract}

Decision-making in colleges and universities in the United States and, I assume, numerous other countries is in a state of despair. It is simultaneously labeled as bureaucratic and authoritarian or overly democratic and permissive; as a collegial community or a divisive political entity; as a tool of the establishment or a weapon of the student radicals. New forms and proposals exist in droves and are under constant discussion. The topic is either a tirade or tiresome; middle grounds are seldom struck.

The purpose of this paper is an attempt to strike a middle ground in its suggestion that appropriate decision structures may be contingent upon the type of decision being made-in its assumption that governance problems are not easily resolved by notions of shared authority, university senates, faculty unions, increased authority, decentralization or the other myriad of bromides, but that it may be a complex combination. The title also suggests that decisions might be evaluated, i.e. determined to be effective. Unfortunately, 
effectiveness implies that the decisions have a goal against which decisions can be judged. No doubt, there are often many goals for a given decision; for example, open admissions may serve a different purpose for different institutions or even be justified for different reasons by faculty groups within the same institution. More helpful, if one is to attempt to evaluate the longerrange effectiveness of a college or university as an organized entity, is to assess its decision-making pattern or process, and not merely its decisions. Unfortunately, evaluating the decision-making process is not just a matter of assessing whether the processes are responsive (decisions get made), are viewed as legitimate, or produce good decisions. Decision processes exist in different organizational environments to which they must relate; i.e. effectiveness of decision-making processes is also contingent on environmental conditions. Evaluation at this level is carried on in other organizations but seldom in higher education. Finally, the paper recognizes the pervasiveness of informal, as well as formal, structures, although this may not be crucial. ${ }^{1}$ Most persons are aware that the informal patterns in colleges and universities are often more important than the formal ones, that the informal ones have a way of being formalized over time, and that they are in practice often inseparable. It would therefore seem more important to know their source and how they influence decision making than to assume that one or the other is more appropriate.

In light of these comments the central focus of this paper might be entitled, "How Do Emergent Conditions in the Decision-Making Environment of Colleges and Universities Affect the Establishment of More Effective Decision-Making Processes?" A threefold response to this question is provided. First, an attempt will be made to highlight some critical emergent conditions or contingencies, both inside and outside of institutions of higher education in the United States, that affect the informal and formal structures and, more importantly, that suggest criteria for evaluating the decision-making processes. Second, an analysis of certain categories of decisions suggests some guidelines for the structure of the decision process and the information technology that might be utilized. Finally, the structures suggested in the second part will be reviewed against the criteria identified in the discussion of emergent conditions. The aim is more to establish a pattern

\footnotetext{
1 The formal structure, I assume, refers to those legally constituted and officially recognized bodies, positions, sanctions, and rules and regulations; i.e. the authority system, which serves as the basis for influencing decisions. The informal structure refers to the influence on decisions possessed by individuals and groups which is based on information or expertise, on personality, on appeals to common values and attitudes, and on control of social rewards or sanctions which are not officially recognized.
} 
for evaluating the effectiveness of decision-making processes than to identify the most appropriate structures.

\section{The Emergent Conditions}

Some critical emerging conditions in higher education in the United States, today, suggest potentially conflicting criteria for effective decisionmaking processes in higher education: (1) the growth of external forces demanding greater control of resources, improved accountability for them, and use of legal guidelines or restrictions in some activities; (2) the expansion within the larger higher education system and at the institutional level of management science-based tools and techniques; and (3) the pressure within institutions for greater participation, decentralization and democratization.

\section{EXTERNAL FORCES}

The external forces affect colleges and universities primarily through two major mechanisms: control of financial and physical resources and control of legal documents, statutes or rulings.

After a period of rapid growth and expanding financial support from state and federal governments, from alumni and private sources, and from student tuition and financial aid in the '50's and ' 60 's, the current financial stringency resulting from a limited tax base, other competing demands for government resources and the economic recession, have introduced increased state legislative and federal agency demands for efficient use of funds and tighter controls on expenditures. State coordination, which grew rapidly in the same period and which has reduced institutional autonomy in some areas, is facing increased legislative pressures to further tighten financial controls within the institution rather than to focus on the more creative planning and coordination activities that many had hoped would be assumed (Berdahl, 1970; Palola et al., 1970). A final force tightening the grip on financial controls has resulted from the federal government's tendency to shift from grants-in-aid, directly distributed to students and faculty members, to institutional grants and, more recently, grants to state and regional agencies, consortia and other compacts.

Three other external forces have had strong impacts on legal rulings affecting higher education. The period of student activism in the last half of the 1960's has hastened the development of state and federal legislative riders to appropriations bills as well as more direct legislative efforts to control student conduct. At the same time courts have been expanding the notion of due process as it relates to student discipline. Also, the recent 
developments in the passage of public employee bargaining laws in many states have hastened the trend toward faculty unionization in many institutions and increasingly brought the institution-faculty member relationship under the purview of the law (O'Neill, 1971).

The net effect of these external forces seems quite obvious. Increasingly, decisions in the areas of student discipline and faculty-employee relationships are stipulated by law or must follow legal guidelines. In the financial area greater demands for responsibility and accountability of persons in specific positions are accompanied by increasingly stringent guidelines. Both the financial and legal restrictions tend to induce not only more formal decision structures but also clearer lines of authority and centralization of authority in college and university administrative positions whose incumbents can then be held responsible.

\section{INTERNAL FORCES}

The conflict of internal and external forces is highlighted by the internal forces' press toward lesser emphasis on authority and centralization. The size of some of our American institutions has led to a consensus that they are either too large or too unmanageable in their present rambling, specialized form in which large numbers of department chairmen may report to one dean, or numerous deans, center and institute directors, etc. may report to one vice president. Student and faculty demands for settings in which they can have improved learning-teaching relationships, demands for more participatory or responsive decision-making, and suspicion or mistrust of persons in administrative positions all contribute to the resistance to authority and centralization. These demands are partially weakened by indications that faculty, while desiring extensive influence, are unwilling to spend substantial amounts of time in governance activities (Dykes, 1968). The emerging practice in the academic area, to rotate or review administrators at fixed periods of time, also suggests a tendency to limit the authority of persons in those positions.

The tendency of these internal forces is thus in the direction of greater decentralization of authority, and toward basing decision-making not on authority in formally established positions but on more informally-based patterns of influence derived from information or expertise, an appeal to common values, or the accepted social norms of the group. The reality, of course, is that students and faculty are often subdivided into interest groups more closely resembling a political interest group system.

\section{THE DEVELOPMENT OF MANAGEMENT SYSTEMS}

The final development which is spurred by the financial stringency of 
the times is the growth and development of managerial science techniques to assist college and university decision-making efforts. While Veblen raised tirades against the "captains of erudition" over fifty years ago, the development of techniques of financial and budget analysis, program-planning and budgeting systems, computer-based management information systems, simulation and forecasting models and the like are all relatively recent arrivals on the higher education scene. They have been spurred in the past five years by consulting firms, by efforts of individuals such as Judy and Levine in their development of the CAMPUS simulation at Toronto, by Ford Foundation grants to Yale, Stanford, Toronto, and other institutions, and most recently, by the USOE through the WICHE Planning and Management Systems program (now National Center for Higher Education Management Statistics). At the institutional level the developments are reflected by the emergence and proliferation of offices of financial analysis, institutional research, directors of administrative data systems and most recently, planning officers at the vice presidential level. The concern, however, is not to raise Veblen's tirade but rather to ensure that this emerging information technology is used in support of the academic decision-making structure which is primarily concerned with the university's major productive activities of teaching, learning and service. Our formal and informal academic decision-making structures must not be made subservient to this information technology. Rourke and Brooks in their study, The Managerial Revolution, have found that centralization of authority is associated with the development of computer-based management systems, thus indicating some reason for concern.

This brief discussion of the three force fields has suggested direct implications for decision-making processes in the areas of financial resource accountability, student rights and dicipline, and faculty-institution relations. More important, however, are the criteria that it suggests for an overall assessment of a college or university's decision-making pattern. First it suggests the desirability for a decision structure which has an authority system that can be responsive to, and account for, resources and legal requirements of external groups. Second, a participation pattern that ensures students and faculty members an opportunity to be influential seems needed. The need to make these two mutually supportive rather than in constant conflict is a corollary criterion. Third, it must be ensured that the information system is integrated into the decision-making structure rather than becoming subservient to it. Finally, the structure probably should provide for decentralization (but with accountability), which is widely in demand, and promises some relief from problems of size, diversity of interests, and teaching-learning needs of faculty and students. 


\section{A Typology of Decisions}

In analyzing a college or university's decision-making system, it is helpful to look at structural and informational requirements which seem to be appropriate for different categories of decisions. Such an analysis is suggested by Herbert Simon (1965) in a discussion in which he holds that all decisions are essentially composed of both a "value" component-an "imperative quality" or "ethical" content-and a "factual" component-"statements about the observable world and the way in which it operates." This view of decisions suggests that information technology and the expertise to deal with the factual component of the decision are extremely useful, providing they do not override the "value" component of the decision. This distinction will thus be utilized to relate the role of information technology to different types of higher education decisions.

The decision typology suggested for this analysis, however, is not one which classifies decisions in the usual higher education categories of financial, academic, personnel, student, facilities and the like, but rather is one which cuts across these more traditional categories and applies to all of them. The three categories to be discussed are policy, managerial, and operating, or control, decisions (Anthony, 1965). The usefulness of these categories lies in the different levels of abstraction which they imply and the differing implications which they suggest for decision-making structure and informational technology. While the discussion of them assumes a university-wide perspective, they apply equally at the college or departmental level, and their implications at those levels will be discussed in the final section.

Policy, managerial and operating decisions can be distinguished along four dimensions in addition to the Simon "fact-value" distinction: the time range over which they apply, the range of individuals or organizational units directly affected, their content, and their means-ends relationships. Each category will be discussed with reference to these dimensions, to the implications for structural and informational technology requirements, and to the examples of structures that most nearly fit the requirements.

\section{POLICY DECISIONS}

Policy decisions are those which are concerned with a university's major goals and priorities, its general program strategies for achieving them, and its strategies for obtaining the resources needed to achieve them. In this sense policy decisions are long term, affect all individuals or units and are primarily concerned with obtaining agreement on desired ends for the institution. Since there is bound to be disagreement on these ends, based more on value concerns than on factual ones, the most appropriate structure is 
probably one which ensures that all points of view are considered, and all possible implications explored, so that compromise or agreement necessary to commitment can be reached. The role of information in policy decisions, while limited, still implies the need for doing comparative studies of other similar institutions; forecasting to assess trends affecting higher education demand and its resource sources; undertaking periodic long-term review of institutional goal achievement and resource utilization; and reevaluation of institutional goals and assessments of overall structure and functions. It would appear that, with few exceptions, colleges and universities engage in little or no overt decision-making or research at the policy level, our current U.S. surplus of Ph.D.'s being a most pregnant example.

While it is possible that a highly respected administrative group could effectively operate as a policy team, its decisions would probably be highly suspect in today's university where student and faculty trust of administration is low. The new university senate model, which includes students, faculty, administration and perhaps trustees or other constituents, offers a promising structure in terms of the demands for participation and the structural requirements for dealing with policy level issues. While these bodies are still at an embryonic stage of development, preliminary studies suggest that they are viewed as representative and do gain substantial commitment and involvement from their student and faculty members. They provide not only a group to assess policy issues but a legitimate sounding board which is readily accessible in crisis situations, such as the necessity of calling in civil authorities. Their problems seem to result from their inability to initiate action-a role which could be filled by the president or other top administrative officers-their lack of adequate administrative staff, and the necessity to deal with detail issues which float to the top (Dill, 1971).

\section{MANAGERIAL DECISIONS}

Managerial decisions focus on issues related to allocation of resources among programs (college level units in a university setting), the coordination of their efforts insofar as they are interdependent, and the mediation of conflicts between and among them. In this sense managerial decisions have a shorter time perspective and may affect fewer units than policy decisions. They also are concerned with development of programs as means of achieving policy. It is at this level that efforts in the fast-expanding information technology to build simulation models for assessing the resource requirements of various program alternatives, program-budgeting systems, cost-benefit analysis techniques and other measurements of program productivity and effectiveness are most useful and, perhaps, most complex. At this level there is generally agreement about priorities (ends), if a policy group 
exists, but there are still disagreements about which programs (means) will best achieve the ends. The value aspect of the decisions is decreased, and fact content increased compared to policy decisions. While the role of information in assessing the alternatives may increase in policy decisions, the role of judgment in interpreting the factual implications will remain nevertheless substantial.

This analysis identifies a decision structure in which there is greater analytic effort required, suggesting the need for an academic administrator who understands the information technology and is not dominated by it. The assumed commitment to policy level priority suggests a decision structure in which substantial agreement exists. However, the difficult analysis and interpretations of the many program alternatives which could be generated suggests that substantial time commitments are required. Further, the wide range of judgment still implies the usefulness of including the many varied perspectives of representatives of different constituencies, although perhaps they are not as numerous as at the policy level. The structure that seems appropriate is that of the executive committee or the working committees related to the policy body in which compromises and workable solutions can be reached.

It should be noted that the faculty bargaining unit or union concerns itself primarily with this level of decision making and the operating level to be discussed next. Although having indirect impact on policy, once a faculty group enters a bargaining arrangement, its primary concerns are usually below the institutional policy level. However, in institutions where faculty have no existing direct influence in policy decisions and little at the program or operating level, a bargaining unit may actually enhance faculty's role in governance as well as provide improved working conditions and financial benefits. The difficulty with the bargaining model, vis-à-vis our initial criteria, is that it fails to provide an effective formal opportunity for students to directly influence decisions at the policy or managerial level.

\section{OPERATING DECISIONS}

Operating decisions are concerned with the way in which program activities are carried out (decisions on whom to admit, schedules of courses, whom to hire or promote, how to spend funds allocated to the program for travel, etc.). The information requirements of such decisions are satisfied by straightforward reports on enrollments, class size, budget statements and the like, which indicate whether resources and activities are being utilized appropriately. The value content of the decision if related to policy guidelines is low, and the factual content high. These decisions can be handled efficiently by routine administrative procedure with occasional review by 
appropriate policy groups. Yet a cursory review of faculty committee structures and activities suggests that these are often the types of decisions on which they spend the most time. This appears to be an inefficient use of faculty time and an expensive way to accomplish the task at hand. Faculty themselves while desiring to be influential, resist spending more time on the decision-making process (Dykes, 1968). Most appropriately these are matters which might be handled by administrative personnel; their use at college and even at departmental levels as administrative assistants is growing in larger universities and has been received favorably once faculty realize they themselves still have substantial influence over policy and are not giving up control of one more of their prerogatives.

\section{An Overview: Related Issues}

This general analysis of decision structures and information technology by decision category has suggested some appropriate ways in which they may be related to satisfy the criterion of integrating the information system within the decision structure. Viewing this set of decision categories at the college or department level suggests the need for training either deans or department chairmen in the use of that technology or for assigning them assistants with such expertise as to assure its integration at the respective levels. A further highlight is the need to keep program structure and the information technology subservient to policy. If effective policy bodies are not established, new programs concerned with their own survival and supported by the rigidities of the information technology's program classification structure may become just as rigid as our old academic units (for a discussion of this dynamic in government, see Moynihan, 1970).

This analysis of decision categories also provides some notion of the structures which seem to meet the internally generated criterion of providing ample student, faculty, and other constituency participation which allows them substantial influence without requiring extensive involvement on all matters. The distinction of the fact and value content of decisions suggests another mode of enhancing faculty involvement and making it more effective. Too often in university decision groups, faculty members have to spend their own expensive, and grudgingly given time on the drudgery of data collection and analysis which could be accomplished by more administrative support. Or more likely, they ignore the "factual" side of the decision issue.

The concern for the externally generated criterion of maintaining positions of authority which can be responsive to the external demands for accountability is not apparent in the analysis. However, several suggestions are implicit. One possible mechanism to ensure identification of admin- 
istrative leaders who can deal with the external demands and yet be sensitive to internal needs is a joint selection committee of higher level administrators with student or faculty constituents. This may provide for better selection of persons, performed by those who are realistically aware of both internal and external forces, than would direct appointment by a higher administrator or selection of nominees by a faculty group. Further, some period of training or concern for administrative development may enhance the growth and development of academic administrators caught in the authority-influence system vise and the growing management technology.

While the notion that rotation of administrators could limit the authority of the person in that position has already been suggested, a procedure calling for the appointment of administrators for a limited period of time, with subsequent review rather than strict rotation, may provide a better possibility of attracting and retaining competent personnel. The practice of reviewing administrators is rare, although instances such as that of President Brewster last year at Yale may set an example.

Finally an increased concern for administrative style may allow administrators to retain their influence while in an authority position. The potential initiating role in policy structure deliberations has already been noted. In smaller units, such as departments, there is strong evidence that a supportive leadership style can enhance the chairman's influence with, and trust by, his faculty even if he merely consults rather than directly involves them (Peterson, 1970). The problem of maintaining the balance of influence and authority, however, is probably as much a matter of educating students and faculty members to, and keeping them aware of, the forces requiring an authoritative response through their involvement on crucial or policy issues as it is a matter of administrative selection, training or definition of the positions of authority.

The final criterion that this analysis has not yet directly considered is the potential for decentralization found in the decision-making structures discussed. The notion that experts in information technology should be placed in major academic units or colleges (even departments), as well as in the central administrative staff, has been mentioned as a device to protect against the centralizing tendencies of development. Additionally, the three categories of decisions inherently provide the potential for decentralization if one recalls that the same decision categories can apply at the school or department as well as the university level. Since managerial and operating decisions flow from policy decisions, the question is merely how much policy autonomy to give to the college and the department. If policy is not decentralized, managerial decisions still can be. The truly centralized institution is one in which even operating level decisions are centralized. The university senate model mentioned in our policy discussion has the potential 
for decentralization if similar units are established at the school and college level. As a matter of fact, it appears that in some institutions which have formed a university senate, it has been necessary to create analogous structures at lower levels merely to keep the university-wide body from becoming inundated with questions which were really only of concern to a particular college. This suggests that as a strategy for developing policy level decisionmaking structures which are both effective and decentralized, one might wish to begin first at the department or college level or at least consider their development simultaneously with that of the university level.

One of the paradoxes of current organizational dynamics in universities is that students and faculty who demand participation in only top-level decision-making bodies may find that they have created a highly centralized structure which either reduces the autonomy of their unit or has little or no effect on it. Another argument for decentralizing policy to the departmental level with student involvement is to make faculty directly aware of the changing conditions of their interdependence; i.e. to make them face open discussions of the student's concern for his marketability in a glutted field and the relevance of his educational experience, to see the administrator's difficulty in obtaining funds, and/or to sense the growing concern of coordinating bodies for planning more completely the use of our public educational facilities. The faculty member's academic freedom may not be eroding, but his autonomy may be without his awareness of it.

While this paper has been addressed to the emergent conditions or contingencies which may determine criteria for evaluating the effectiveness of decision-making processes in the years ahead and has tried to relate some decision categories to appropriate decision-making and information technology structures, it has not directly considered some of our current crucial questions.

1. To what extent can crisis decisions be covered by policy or handled by an all-university senate or other structure?

2. Can any internal decision-making body make program cutbacks in some seemingly obsolete areas to permit institutional progress in a time of financial stringency and reduced growth?

3. If bargaining is the only way for faculty to get their fair share in the political distribution of public monies, is there any way that they can still retain a strong policy role? Or that students can be influential?

These questions and the capacity of the decision-making system to deal with them may constitute even longer-run criteria for evaluating this or any other decision-making model. 


\section{TYPES DE DECISION, STRUCTURES ET EVALUATION DES \\ PROCESSUS: UN MODELE DE CONTINGENCE}

\section{Résumé}

Les projets officiels pour l'enseignement supérieur sont souvent formulés aux Etats-Unis par référence à un objectif idéal ou en supposant qu'un projet déterminé est susceptible de représenter la solution universelle de problèmes multidimensionnels et qu'il est également réalisable dans les différents contextes institutionnels. L'article ne vise pas à présenter un projet particulier; il se place au point de vue analytique et présente un modèle à éventualités multiples capable de déterminer les structures les plus appropriées à la prise de décision. En premier lieu, les caractéristiques nouvelles du milieu social dans lequel fonctionne aux Etats-Unis l'enseignement supérieur, les caractéristiques du milieu interne constitué par les collèges et les universités et les caractéristiques des systèmes de gestion pour l'Université sont soumises à l'examen afin de déterminer une large gamme de critères capables de s'appliquer à l'évaluation de l'efficacité des décisions. En second lieu, on présente une typologie des décisions institutionnelles dont les catégories sont celles de la détermination d'une politique, de la gestion et de l'application. L'analyse de la nature et du contenu de chacun des principaux types de décisions conduit à concevoir des structures et des formes différentes pour les prises de décision, tant explicites que diffuses, ainsi que des caractéristiques et des fonctions différentes pour la technologie de l'information sur laquelle repose la gestion, cela par référence aux différentes catégories de décision. En dernier lieu, l'analyse met en relations les notions variables de structure et de type de décision avec les critères retenus pour évaluer le processus de la prise de décision et examine jusqu'à quel point ils sont compatibles ou pourraient être modifiés afin de devenir plus compatibles. Le modèle présenté est un modèle théorique très général dont l'auteur suggère qu'il pourrait être utilisé tant pour une institution de large envergure que pour les sous-ensembles d'un collège ou d'une université.

\section{References}

Anthony, R. (1965). Planning and Control Systems. Cambridge: Harvard Graduate School of Business Administration.

Berdahl, R. (1970). Statewide Coordination of Higher Education. Washington, D.C.: American Council on Education.

Dill, D. (1971). Case Studies in University Governance. Washington, D.C.: National Association of State Universities and Land-Grant Colleges.

Dykes, A. R. (1968). Faculty Participation in Academic Decision Making. Washington, D.C.: American Council on Education. 
Johnson, C. and Katzenmeyer, W. (1969). Management Information Systems in Higher Education. Durham: Duke University Press.

Katz, D. and Kahn, R. (1966). The Social Psychology of Organizations. New York: Wiley.

Moynihan, D. (1970). "Policy versus program in the '70's," Public Interest (Summer): No. 20, 90-100.

O'Neill, R. (1971). "The eclipse of faculty autonomy." Paper at Campus Governance Conference, Houston, February 18.

Palola, E. et al., (1970). Higher Education By Design. Berkeley: Center for Research and Development in Higher Education, University of California.

Peterson, M. W. (1970). "The organization of departments. Research Report No. 2." College And University Bulletin (December 1).

Rourke, F. and Brooks, G. (1966). The Managerial Revolution in Higher Education. Baltimore: Johns Hopkins Press.

Simon, H. (1965). Administrative Behavior. Ch. 3. New York: Free Press.

Thompson, J. (1963). Comparative Studies in Administration. Pittsburgh: University of Pittsburgh. 